\title{
Exploring the efficiency of the Tilburg Frailty Indicator: a review
}

\author{
This article was published in the following Dove Press journal: \\ Clinical Interventions in Aging \\ 19 October 2017 \\ Number of times this article has been viewed
}

\author{
Robbert JJ Gobbens ${ }^{1-3}$ \\ Jos MGA Schols ${ }^{4}$ \\ Marcel ALM van Assen ${ }^{5,6}$ \\ 'Faculty of Health, Sports and Social \\ Work, Inholland University of Applied \\ Sciences, Amsterdam, the Netherlands; \\ ${ }^{2}$ Zonnehuisgroep Amstelland, \\ Amstelveen, the Netherlands: \\ ${ }^{3}$ Department of General Practice, \\ University of Antwerp, Antwerp, \\ Belgium; ${ }^{4}$ Department of Health \\ Services Research and Department \\ of Family Medicine, CAPHRI-Care \\ and Public Health Research Institute, \\ Maastricht University, Maastricht, \\ the Netherlands; ${ }^{5}$ Department of \\ Methodology and Statistics, Tilburg \\ School of Social and Behavioral \\ Sciences, Tilburg University, Tilburg, \\ the Netherlands; ${ }^{6}$ Department of \\ Sociology, Utrecht University, Utrecht, \\ the Netherlands
}

\begin{abstract}
Due to rapidly aging human populations, frailty has become an essential concept, as it identifies older people who have higher risk of adverse outcomes, such as disability, institutionalization, lower quality of life, and premature death. The Tilburg Frailty Indicator (TFI) is a user-friendly questionnaire based on a multidimensional approach to frailty, assessing physical, psychologic, and social aspects of human functioning. This review aims to explore the efficiency of the TFI in assessing frailty as a means to carry out research into the antecedents and consequences of frailty, and its use both in daily practice and for future intervention studies. Using a multidimensional approach to frailty, in contexts where health care professionals or researchers may have no time to interview or examine the client, we recommend employing the TFI because there is robust evidence of its reliability and validity and it is easy and quick to administer. More studies are needed to establish whether the TFI is suitable for intervention studies not only in the community, but also for specific groups such as patients in the hospital or admitted to an emergency department. We conclude that it is important to not only determine the deficits that frail older people may have, but also to assess their balancing strengths and resources. In order to be able to meet the individual needs of frail older persons, traditional and often fragmented elderly care should be developed toward a more proactive elderly care, in which frail older persons and their informal network are in charge.
\end{abstract}

Keywords: frailty, Tilburg Frailty Indicator, measurement instruments, psychometric properties, elderly care

\section{Introduction}

Due to better living conditions and advancements in both medicine and technology, life expectancy of people has increased progressively during the last decades. ${ }^{1}$ Current demographic projections for most Western countries show that the proportions of old and very old people will continue to grow. ${ }^{1}$ To deal with the challenges resulting from this aging population, policies and services are more and more focusing on independent living in the community rather than relying on institutions, such as residential homes and nursing homes. ${ }^{2}$ Moreover, this fits in the wishes of most older people, who prefer to live in their own familiar environment for as long as possible. ${ }^{3,4}$ Therefore, the phenomenon of "aging in place" has become very popular and trendsetting for the government policies of Western countries. ${ }^{5}$

Aging in place is commonly used to refer to people growing old in their own homes, but more recently, this term has broadened to remaining in the current community and living in the residence of an individual's own choice. ${ }^{3}$ Aging in place is designed to prevent or delay traumatic transitions for older people to an institutional care facility. In addition, quality of life of older people seems to benefit from this aging in place, because one's autonomy is maintained ${ }^{6}$ as well as one's social relationships, such as

\footnotetext{
Correspondence: Robbert J Gobbens Faculty of Health, Sports and Social Work, Inholland University of Applied Sciences, De Boelelaan I 109, 108I HV Amsterdam, the Netherlands Tel +3 I 62 III 5578

Email robbert.gobbens@inholland.nl
} 
friendship with neighbors. ${ }^{7}$ Fundamental aspects for aging in place are independency, a certain degree of competence, and control over one's environment. ${ }^{5}$ Besides the preferences of older people themselves, aging in place is also often considered to be less expensive than inpatient elderly care ${ }^{8}$ making it a possible cost-effective solution for a future-proof long-term care for older people.

Because of the rapid aging of human populations, frailty has become an important and commonly accepted concept, since it identifies older people who have higher risk of adverse outcomes, for example, institutionalization, ${ }^{9}$ hospitalization, ${ }^{10}$ falls,${ }^{10}$ lower quality of life, ${ }^{11}$ disability, ${ }^{12}$ and premature death. ${ }^{13}$ Frailty is associated with a 1.2- to 1.8-fold risk of hospitalization, a 1.2- to 2.8-fold risk of falls and fractures, a 1.6- to 2.0-fold risk of activities of daily living (ADL) disability, and a 1.8- to 2.3-fold risk for mortality. ${ }^{14}$ Frailty is increasingly recognized as a target for the prevention of adverse outcomes in older people, both in clinical practice and research. ${ }^{15}$

However, currently, there is still no clear consensus regarding both the conceptual and operational definition of frailty. ${ }^{15,16}$ The ongoing debate mainly focuses on whether frailty should be considered primarily as losses in physical functioning or psychologic and social functioning should be included as well. Currently, more and more researchers, health care professionals, and policymakers are becoming convinced that frailty is multidimensional and that physical, psychologic, and social aspects of human functioning should be assessed. The World Health Organization recommends this holistic approach to aging and the care of frail older people. ${ }^{17}$ This approach should also pay attention to the capabilities that frail older people still have.

While recognizing the multidimensional nature of frailty, it is important to have an operational definition of frailty that is simple enough to be used clinically and to guide prevention and suitable care in older people. ${ }^{17}$ The Tilburg Frailty Indicator (TFI), a user-friendly questionnaire that originally was developed for identifying frail community-dwelling older people, expresses this multidimensional approach of frailty. ${ }^{18}$ Recently, a systematic review concluded that the TFI has the most robust evidence of reliability and validity, and the TFI has been the most extensively examined in terms of psychometric properties among 38 multicomponent frailty assessment instruments, defined as an instrument that assesses at least two components of frailty. ${ }^{19}$

This study is aimed at exploring the efficiency of TFI in assessing frailty, as a means to carry out research into the antecedents and consequences of frailty, and its use both in daily practice and for future intervention studies. Successively, we will describe the background of the TFI (development, content, scoring), the psychometric properties of the instrument, and its comparison with other frailty instruments. We will then go into more detail on how the TFI distinguishes itself from other instruments. In the last sections, we will pay attention to its practical usability, consider the TFI in the context of proactive elderly care, and we will make recommendations for future research.

\section{Background of the TFI}

\section{An integral conceptual model of frailty}

The TFI is based on an integral conceptual model of frailty (Figure 1), ${ }^{20}$ which is a refinement of a model developed by a group of Canadian researchers. ${ }^{21}$ The integral conceptual model of frailty describes the pathway from life course determinants and disease(s) to frailty and then to adverse outcomes. Although an overlap exists between frailty, ADL disability, and multimorbidity, it was agreed that these three concepts need to be separated from each other, which is in agreement with Fried et al. ${ }^{22}$ Mostly, ADL disability is regarded as an adverse outcome of frailty, ${ }^{21,23}$ whereas frailty is considered a pre-disability state by the European, Canadian, and American geriatric boards. ${ }^{24}$ Multimorbidity is mainly considered as an antecedent of frailty. ${ }^{22}$ Finally, Xie et $\mathrm{al}^{25}$ noted that treating disability and multimorbidity as frailty components may confound the interventions designed to prevent or mitigate frailty.

The 10 life course determinants (eg, sex, income, lifestyle, life events) and the adverse outcomes (disability, health care utilization, death) were selected on the basis of previous research on frailty. ${ }^{20}$ The core of the model is formed by physical, psychologic, and social frailty and their associated components. These components were selected based on the literature study and consultation of 17 experts in the field of frailty. ${ }^{26}$ Arrows are placed between the physical, psychologic, and social domains of frailty to make clear that these domains can be distinguished as different domains, but do not exist in isolation, and as a reminder that the focus should be on the person as a whole. In addition, the model lists the times when both health care and well-being professionals can intervene, indicated by the vertical arrows in the model, for example, health promotion and prevention are intended to prevent or delay the onset of frailty.

\section{The content and scoring of the TFI}

The first draft of the TFI was presented to 91 participants at two geriatric meetings in 2008, representing several 


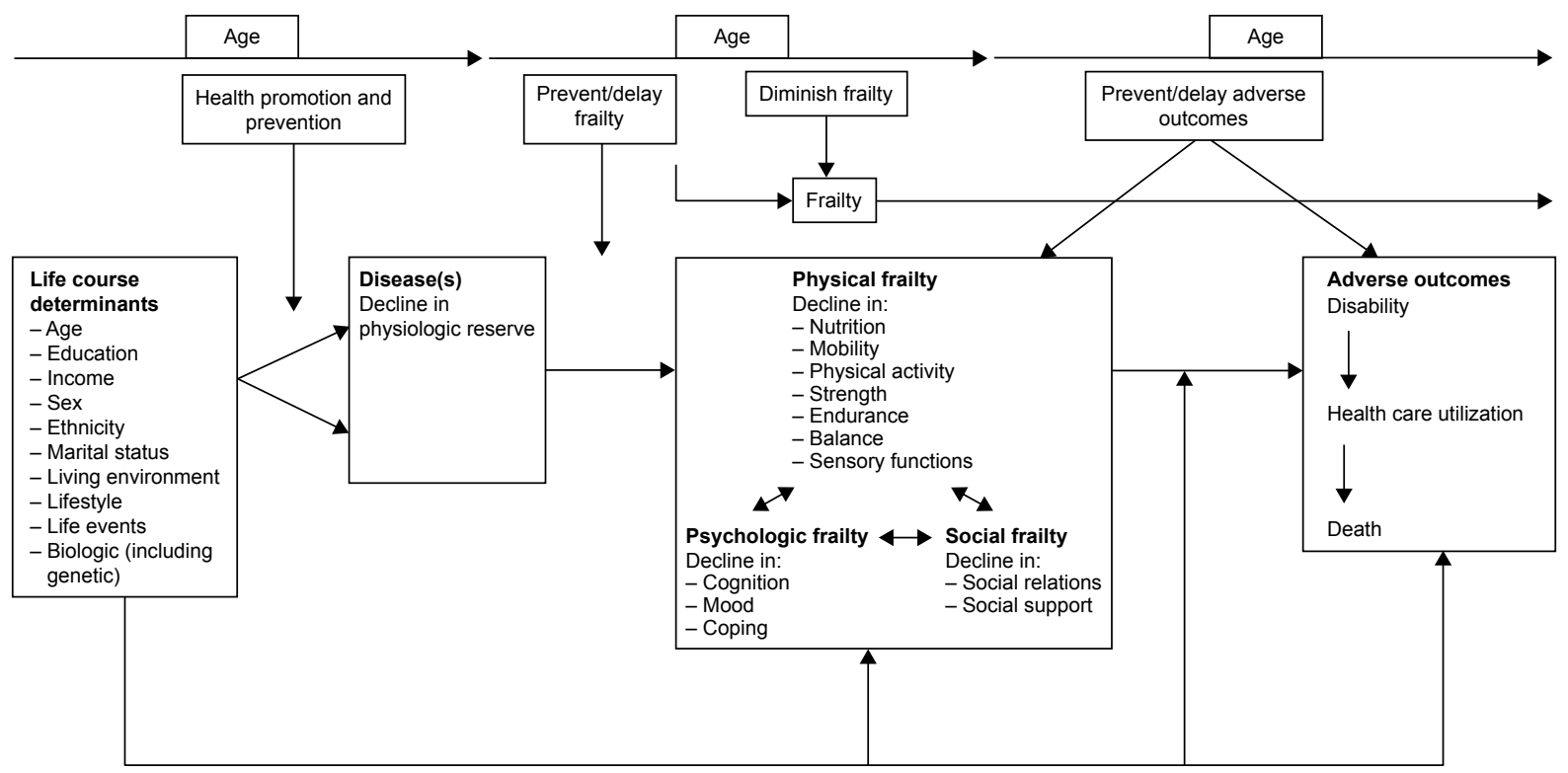

Figure I An integral conceptual model of frailty.

Note: Reproduced from Gobbens RJ, Luijkx KG, Wijnen-Sponselee MT, Schols JM. Towards an integral conceptual model of frailty. J Nutr Health Aging. 20I0;I4(3): I75-I8I. ${ }^{20}$

disciplines, such as medicine, nursing, and social work. The participants were asked whether they felt any components of frailty were missing. Their responses resulted in changes in the determinants, components, and answering categories. In addition, we decided to change the format of the TFI into two parts: part A, determinants of frailty and part B, components of frailty. Then, the second draft of the TFI was presented to 10 representatives of professional disciplines as well as to 33 people aged 75 years and older. No changes were made, since both groups indicated that no components of frailty were missing and that the questions of the TFI were clear.

The final version of the TFI was constructed in 2008 and first published in 2010; it contains 10 determinants, including disease(s) (part A), as shown in Figure 1, and 15 components of frailty (part B). ${ }^{18}$ Because the integral model of frailty excludes disability and comorbidity, the 15 components only refer to the three domains of frailty. The following eight components refer to physical frailty: physically unhealthy, unexplained weight loss, difficulty in walking, difficulty in maintaining balance, poor hearing, poor vision, lack of strength in the hands, and physical tiredness. Four components refer to psychologic frailty: problems with memory, feeling down, feeling nervous or anxious, and unable to cope with problems. Social frailty consists of three components: living alone, lack of social relations, and lack of social support.

Eleven items have two response categories, "yes" and "no", and four items also have the response category "sometimes". After recoding, the scales are obtained with ranges
0-15 (total frailty), 0-8 (physical frailty), 0-4 (psychologic frailty), and 0-3 (social frailty). For a detailed description of the TFI, refer to the Supplementary material.

\section{Psychometric properties of the TFI}

Recently, a systematic review by Sutton et a $1^{19}$ concluded that out of 38 frailty assessment instruments, the TFI was the most extensively examined in terms of its psychometric properties. We summarized the results of these examinations of the TFI, in terms of face and content validity, internal consistency and test-retest reliability, construct validity (ie, convergent and divergent validity), determinants of frailty including reference scores or norms, and its predictive validity. The results on face and content validity, reliability, and construct validity are primarily based on the study by Gobbens et al. ${ }^{18}$ Research on determinants of frailty and predictive validity was inspired by the integral model of frailty, ${ }^{27,28}$ supplemented with results from other studies.

The face and content validity of the TFI was guaranteed by the development of the TFI as described in the background section; with the integral model in mind, the 15 components of frailty were determined after several consultations with experts from both disciplines and older persons. Internal consistency reliability (using Cronbach's $\alpha$ ) was 0.73 for total frailty, 0.70 for the physical domain, 0.63 for the psychologic domain, and 0.34 for the social domain in a Dutch sample of 479 community-dwelling persons of 75 years and older. ${ }^{18}$ We do not consider the low internal consistency of the social domain a problem, because we want the TFI to cover the 
most important elements of frailty and its domains in as few questions as possible (which is only three in the case of the social domain; note that internal consistency increases with the number of indicators), and therefore consider test-retest reliability as more important. The test-retest reliabilities of total frailty (0.79) and its three domains (0.67-0.78) were good for a 1-year period in the same sample.

The same sample was also used to assess the TFI's convergent and divergent validity, employing physical measures of frailty as well as several questionnaires and questions related to the three frailty domains. ${ }^{18}$ The convergent validity of TFI's domains was evaluated as good, since all domains correlated as expected and statistically significantly with the corresponding measures. Divergent validity was generally also confirmed because correlations of domains with the corresponding measures were stronger than with measures related to other domains. The only exception was the MiniMental State Examination of various dimensions of cognition, which was more strongly correlated with the physical domain than the psychologic domain. The latter finding confirms that physical frailty is associated with low cognitive performance, ${ }^{29,30}$ and that physical and psychologic frailty are quite strongly correlated (correlation about equal to 0.45 in a sample of more than 35,000 community-dwelling Dutch persons older than 65). Because we doubted the validity of the TFI question “Do you feel physically healthy?" for measuring physical activity, we have changed the question to "Do you find that you can be sufficiently physically active?"18,31

Seven determinants of frailty (age, sex, marital status, ethnicity, education, income, location) together explained a medium to large part of the variance of total frailty $(20.2 \%)$, physical frailty (17.9\%), and social frailty (14.4\%) and a smaller part (6.7\%) of psychologic frailty in a sample of more than 35,000 community-dwelling Dutch persons older than 65 years, living in the city of Amsterdam and the provinces Zeeland and Noord-Brabant (small cities and more rural areas). ${ }^{32}$ Using this large sample, women and people with a non-Dutch ethnicity were shown to be more frail than men, and a higher education, higher income, lower age, and being married were associated with less frailty. The effect of age was strong on total frailty and captured well with a positive quadratic trend. Reference scores or norms were established for total frailty and physical frailty as a function of age, for (Dutch) men and women separately, which will help interpreting individuals' TFI scores. ${ }^{32}$ This large study revealed some very large average frailty differences across ethnic groups, with Turks having the highest total frailty, Turks and Moroccans having the highest physical and psychologic frailty, and Surinam people having the highest social frailty. With regard to the integral model of frailty, using a smaller sample, it was established that multimorbidity, indeed, partly mediates the effects of the determinants on total, physical, and psychologic frailty. ${ }^{28}$

The predictive validity of TFI total frailty and its domains for the adverse outcomes in the integral model has been established in several cross-sectional studies and longitudinal studies with different time intervals using different samples in different countries such as Brazil, ${ }^{33}$ Portugal, ${ }^{34}$ Poland, ${ }^{35}$ and Italy. ${ }^{36,37}$ For instance, a cross-sectional study using a Dutch sample of 213 community-dwelling people aged 75 years and older showed that the frailty domains were associated with disability, visits to a general practitioner, contacts with health care professionals, four quality of life domains (physical health, psychologic, social relationships, environmental), receiving personal care, receiving informal care, and facilities in residential care. ${ }^{38}$ These associations have also been established in longitudinal studies. ${ }^{23,27,34,39,40}$ A recent longitudinal prospective population-based study using 1,278 French people who were initially 65 years or older and noninstitutionalized showed that the TFI predicted both death and falls over a period of 12 years. ${ }^{41}$

After assessing the predictive validity of the TFI using the data of a Dutch sample of 234 community-dwelling persons 75 years and older, it was decided that a total score of 5 or more was the best cutoff point for assessing someone as frail. ${ }^{18}$ Using a cutoff point of 5 , reference scores were determined as a function of age for both sexes separately, based on a sample of more than 35,000 community-dwelling Dutch persons older than 65 years. ${ }^{32}$ The estimated prevalence of frailty in community-dwelling older persons varied from $7.5 \%$ among men and $12.6 \%$ among women at age $65-66$, increasing more than linearly to $11.0 \%$ and $15.6 \%$ at age $71-72,16.6 \%$ and $22.1 \%$ at age $77-78$, and $23.4 \%$ and $31.6 \%$ at age $83-84 .^{32}$

Because the TFI is a very easy-to-administer self-report assessment instrument, a relevant question for practical use is whether the TFI may replace more costly and time-intensive interviews, a comprehensive geriatric assessment, and physical measures when diagnosing frailty and predicting adverse outcomes. This relevant question was assessed by testing the hypothesis that TFI's prediction of the adverse outcomes disability and health care utilization is not improved after adding the physical measures of frailty and measures derived from personal interviews using structured questionnaires. ${ }^{39}$ Using a Dutch sample of 245 community-dwelling persons aged 75 years and older assessed at baseline, 1 year, and 2 years 
later, it was concluded that physical measures and measures derived from interviews did not improve the prediction of most health care utilization indicators. The two exceptions were disability, the prediction of which was improved using the Timed Up and Go test, and contacts with health care professionals, the prediction of which was improved using the Hospital Anxiety and Depression Scale. ${ }^{39}$ Overall, we conclude that the easy-to-administer TFI may be a cost-efficient instrument to use to assess frailty for several purposes. Examples include large-scale research on the prevalence of frailty, associations of frailty with both antecedents and adverse outcomes of frailty, and examinations where the health care professional may have no time or too limited time to interview or examine the client. In situations where the contact time between health care professional and client is not limited, we recommend a more full examination of the frailty of the client by using both physical measures and instruments including more indicators (see the next section).

Whereas initial research on the psychometric properties of the TFI has been carried out using Dutch samples, properties of translated versions of the TFI have also been examined recently. ${ }^{33,34,42-48}$ We must note, however, that examinations of these translated versions are based on a single study or a few studies, and did not address all psychometric properties (test-retest reliability, construct validity, predictive validity, reference scores) that we deem relevant. Hence, research on the TFI and its properties is far from complete.

\section{Comparison between the TFI and other frailty instruments}

Three main approaches have been used to assess frailty. The first approach is the Cardiovascular Health Study (CHS) Phenotype Model, ${ }^{10}$ which is exclusively focused on physical frailty. The Phenotype Model has been developed by Fried et al, and according to this model, a person is identified as frail if he or she meets at least three of the following criteria: unintentional weight loss, poor endurance, slowness, low physical activity, and weakness. ${ }^{10}$ In addition, a person is pre-frail if two of the aforementioned criteria are present. Other well-known instruments based on the first approach include the Study of Osteoporotic Fractures Index, ${ }^{49}$ the FRAIL scale ${ }^{50}$ and the Physical Frailty Index. ${ }^{51}$ The second approach is the Canadian Study of Health and Aging Cumulative Deficit Model. ${ }^{52}$ The Frailty Index (FI) developed by Mitnitski et $\mathrm{al}^{52}$ is based on the Cumulative Deficit Model. The FI is an index of age-related deficits (at least 30) including disability and diseases. Other instruments based on the second approach include the Evaluative Frailty Index for
Physical Activity ${ }^{53}$ and the 70-item FI (Survey of Health, Aging and Retirement in Europe). ${ }^{54}$

The third approach is the multidimensional model, which defines frailty as a dynamic state affecting an individual who experiences losses in one or more domains of human functioning (physical, psychologic, social). ${ }^{16,26}$ Examples of frailty instruments belonging to the latter approach are the Strawbridge questionnaire, ${ }^{30}$ the Sherbrooke Postal Questionnaire, ${ }^{55}$ the Groningen Frailty Indicator, ${ }^{56}$ the Edmonton Frail Scale, ${ }^{57}$ the Health Status Form, ${ }^{58}$ and the TFI. ${ }^{18}$ Finally, aside from the three most common approaches, some instruments have operationalized frailty mainly as the presence of ADL disability, for example, the Frail Elderly Functional Assessment Questionnaire ${ }^{59}$ and the Vulnerable Elders Survey. ${ }^{60}$ See Aguayo et al ${ }^{61}$ for an overview of 35 frailty instruments in the general population, including the TFI, and the approaches on which they are based. Bouillon et $\mathrm{al}^{62}$ concluded that the most widely used frailty instruments are "the Phenotype of frailty"10 and "the FI", 52 but none of the 27 measures they examined have been recognized as a gold standard.

Currently, five systematic reviews and four reviews concerning the comparison of characteristics of frailty measurement instruments have been carried out. ${ }^{19,25,63-65}$ The first review was conducted by de Vries et $\mathrm{al}^{64}$ in 2011; this research group gave an overview of the content of 20 frailty instruments and described their reliability and validity. Based on previous studies ${ }^{20,26,28,66}$ and after ample discussion, they composed a list of eight frailty factors that are mentioned to be of great importance to the concept of frailty: nutritional status, physical activity, mobility, strength, energy, cognition, mood, and social relations/social support. ${ }^{64}$ Six years later, Xie et $\mathrm{al}^{25}$ showed that the most frequently reported components in instruments of frailty were mobility and balance, nutrition, and cognitive function. Fifteen of 49 frailty measures included components across all three domains (physical, psychologic, social/environmental domains); ${ }^{25}$ one of these instruments is the TFI. ${ }^{18}$

Four reviews are mainly focused on the psychometric properties of frailty instruments. ${ }^{19,63,65,67}$ The review by Clegg et $\mathrm{al}^{63}$ investigated the diagnostic test accuracy of simple instruments for identifying frailty in community-dwelling older people. It was shown that among seven frailty instruments, slow gait speed, ${ }^{68}$ the tool of the Program on Research for Integrating Services for the Maintenance of Autonomy-7, ${ }^{69}$ and the Timed $\mathrm{Up}$ and $\mathrm{Go}^{70}$ had high sensitivity for identifying frailty. ${ }^{63}$ Pijpers et al ${ }^{65}$ reviewed five frailty instruments, including the CHS Phenotype Model ${ }^{10}$ and the Study of 
Osteoporotic Fractures Index, ${ }^{49}$ and concluded that since the number of false-positive values for identifying frailty in community-dwelling older people of most available instruments is substantial, they are of limited value for screening as well as for diagnostic purposes in daily practice. In the reviews by both Clegg et $\mathrm{al}^{63}$ and Pijpers et al, ${ }^{65}$ the TFI was excluded.

A recent systematic review focusing on the psychometric properties of frailty measurement instruments was performed in 2016 by Sutton et al. ${ }^{19}$ The objective of this study was to identify existing multicomponent frailty assessment instruments that were specially developed to assess frailty in adults aged 60 years and older, and to systematically and critically evaluate both the reliability and the validity of these instruments. Thirty-eight multicomponent frailty measurement tools were identified, of which only two instruments had sufficient evidence of validity and reliability, and of fair-excellent methodological quality: the Frailty Index-Comprehensive Geriatric Assessment ${ }^{71}$ and the TFI. ${ }^{18}$ Apostolo et al ${ }^{67}$ found that only a few frailty measures seem to be valid, reliable, and diagnostically accurate, and have good predictive ability. The first is the FI, ${ }^{52}$ however, the TFI ${ }^{18}$ also showed good properties. Finally, Pialoux et $\mathrm{al}^{72}$ concluded that the TFI ${ }^{18}$ and the Frailty Instrument for Primary Care of the Survey of Health, Aging and Retirement in Europe ${ }^{73}$ are the best instruments for screening frailty in primary health care settings.

Because of the diversity of frailty assessment instruments' starting point (physical or multidimensional), form (including physical measurements or just self-report), content (ie, indicators used), and number of indicators, it will come as no surprise that they differ widely in the people they identify as frail. ${ }^{41,61}$ For instance, in a longitudinal study using a French sample of 1,278 participants that examined the Phenotype Model, ${ }^{10}$ the FI, ${ }^{52}$ and the TFI $,{ }^{18} 46.5 \%, 13.2 \%$, and $23.7 \%$ of participants were identified as nonrobust (frail and pre-frail), respectively. ${ }^{41}$ Concordance was low, since only $52.0 \%$ of participants were similarly classified by all three instruments. Another study comparing 35 published frailty scores also found a very wide range of agreement between these scores and concluded, "Different frailty scores are based on different concepts of frailty, and most pairs cannot be assumed to be interchangeable. Research results based on different frailty scores cannot be compared or pooled." 61 We agree with this conclusion.

The use of a frailty instrument should always be in accordance with the aim for which the instrument was designed. ${ }^{64,74}$ As such, the added value of instruments depends on the context. For instance, the Phenotype Model defines the presence/absence of a risk condition for adverse outcomes and supports clinical practice to decide which interventions have to be performed, and the $\mathrm{FI}^{52}$ acts as a measure of the capacity of the human being; it tells us how many clinical conditions are present and occur at exhausting reserves. ${ }^{74}$ For intervention purposes, Xie et $\mathrm{al}^{25}$ render frailty instruments out of date that include disability and comorbidity or multimorbidity, for example, the Groningen Frailty Indicator ${ }^{56}$ and the Health Status Form, ${ }^{58}$ because they may confound the interventions designed to prevent or mitigate frailty. According to de Vries et al, the setting, the qualities of the person who administers the instrument, and the time available should also be taken into consideration when making a choice for using a particular instrument for measuring frailty. ${ }^{64}$

To conclude, many different frailty instruments exist, greatly varying in approach, assessment method (use of self-report, interviews, performance tests, clinical judgment, or combinations of these), and in their identification of frail persons. On the one hand, we believe this lack of agreement in approaches and assessment may hamper scientific progress, communication between practitioners, and even care for older frail persons. On the other hand, we recognize that different aims ${ }^{64,74}$ and different settings including time available and qualifications of the person administering the instrument ${ }^{64}$ also matter for both approach and assessment. Nevertheless, we believe both science and practice may benefit from some general guidelines. Using a multidimensional approach of frailty, in contexts where health care professionals or researchers may have no time to interview or examine the client, we recommend employing the TFI because it has the most robust evidence of reliability and validity and is easy and quick to administer. However, overviews of several instruments suggest that the TFI does not have the highest reliability and is not the best predictor of all adverse outcomes of frailty. For instance, the FI, with its higher number of indicators (at least 30), outperforms the TFI in prediction ${ }^{41,67}$ and will have higher reliability scores. Therefore, in contexts where clients are assessed by practitioners or scientists with unrestricted or lenient time constraints, we recommend using the $\mathrm{FI}^{52}$ or more extensive examinations to establish the frailty of the client.

\section{Practical usability of instruments such as the TFI}

\section{A policy model of inclusive elderly care}

The diversity of frail older persons is the result of the multidimensional nature of their care needs. This multidimensionality of needs necessitates a multidisciplinary approach 
transcending different sectors. However, this is difficult to achieve in many of the current Western elderly care systems, which are frequently hampered by fragmentation of the care provision. ${ }^{75}$ Consequently, respecting the trend toward empowered frail older persons aging in place stresses the urgent need for a proactive, inclusive, and interdisciplinary care system that, after early detection of frailty or a disturbed frailty balance, responds to the complex needs of people in a holistic fashion. In such a care system, both the care recipients and care providers are strong advocates of collaboration between diverse sectors such as (mental) health and social care, housing, and urban planning.

In the last decade, the focus has already moved promisingly toward a broader integration across different levels of medical care and public health, social and other support services, such as housing and education at the community level. ${ }^{76}$ Emerging frailty may negatively impact aging in place and cannot be resolved with a reactive geriatric care. Aging in place, therefore, requires a trend toward a proactive care for older people, starting with the early detection of frailty. The TFI may be used for early screening of multidimensional frailty and to assess whether someone needs both a more comprehensive and an integral geriatric multidimensional assessment as well as a care needs assessment, which can be followed by tailored, personalized interventions aimed at preventing avoidable deterioration of the situation leading to adverse outcomes or at least aiming for maintenance of the situation.

\section{Frailty balance}

The current literature on frailty mostly considers frailty as a decline in health and function. ${ }^{77}$ The often negative image of being a "dependent" recipient of care leads to exclusion. ${ }^{78,79}$ Frailty is mostly interpreted as a negative construct, a construct of deficits, expressed by many frailty measurement instruments, for example, the CHS Model, ${ }^{10}$ the FI, ${ }^{52}$ and the TFI, ${ }^{18}$ while it could also be seen as a more positive concept, such as receptiveness. Even people who are frail may achieve a state of well-being and can be resilient. Resilience has been described as a resource to cope with changing circumstances. ${ }^{80}$ It can be defined as a dynamic process by which people react to environmental forces. Additionally, resilience has also been studied as a trait focusing on physical and psychologic characteristics to endure adversity or on individual adaption that positively influences the process of successful aging. ${ }^{81}$ As the aging process consists of an ongoing renegotiation of sense of self, relationships with others and with place(s), frailty management should aim at reinforcing coping capabilities, resilience, and supportive circumstances in the physical, psychologic, and social domains. ${ }^{82}$ This perspective also allows the focus to be shifted from rather automatic formal care to the perspective of older people themselves, since they are the key figures in their own life. ${ }^{83,84}$

The importance of this so-called "frailty balance" concept, which has been described as intervening in the balance between losses and deficits on one side and support and autonomy on the other side, had already been referred to by Sipsma in $1986 .{ }^{85}$ Two individuals with the same frailty profile may have a different frailty balance because of the kind of support they need and have at their disposal. ${ }^{85,86}$ With regard to a more positive approach by using the concept of the frailty balance, several studies discovered that older people can still have a satisfying life, despite their deficits. ${ }^{42}$ For example, frail older people experiencing physical and/or social changes may still report good levels of psychologic well-being. ${ }^{87}$ Similarly, a Dutch study showed that almost half of frail participants still report a good to excellent quality of life. ${ }^{88}$

The future will show whether current frailty screening (eg, screening with an instrument like the TFI) may be complemented by screening of the intrinsic power of frail older people or will develop toward an assessment of the frailty balance.

\section{Targeted interventions on frailty}

In our opinion, screening using the TFI can provide a first direction to the interventions that should be carried out next. In general, the treatment for frailty consists of many possible unidomain interventions as well as multidomain interventions. Nowadays, the focus is increasingly on multidomain interventions to target multiple affected functions in order to decrease the risk of adverse outcomes of frailty or to restore the frailty balance. Evidence of the effects of multidomain compared to unidomain interventions is limited, but increasing. ${ }^{89}$ Next to group interventions, currently there is also more interest in adapting a person-centered, empowering approach that is perceived as a fundamentally new paradigm for the provision of services to older people, in particular, and frail people, in general. ${ }^{90}$ The motives for this approach revolve around the autonomy of an individual, assuming maximum decision-making power and control over care negotiations. ${ }^{91}$ Even when frail people lose control or are unable to impact their surroundings, they strive to manage their frailty and remain engaged in their community. ${ }^{92}$ This also makes frail older persons equal partners in care and 
shared decision making, which in turn provides a basis for personalized care as a result of acknowledging the uniqueness of each individual older person.

\section{Future research directions}

Presently, no existing frailty instrument is considered to be a gold standard ${ }^{65}$ Although the psychometric properties of the TFI have been extensively examined using, in particular, Dutch community-dwelling samples, translating the TFI to other languages, and more research on its properties in other samples (eg, hospitalized older people) and countries are still required. For a frailty assessment instrument to meet the requirements of a gold standard, it must be based on a universally accepted operational definition of frailty and have evidence pertaining to all aspects of the instrument's reliability and validity of high methodological quality. ${ }^{15}$ Currently, no universally accepted definition of frailty exists, and although a recent review concluded that the TFI has the most robust evidence of reliability and validity, it concludes that the TFI does not yet have sufficient evidence of high methodological quality. ${ }^{19}$ In our opinion, the number of frailty instruments should be limited and the best instruments should at least partly be selected based on their psychometric properties. We believe that the TFI has the potential to be one of these instruments.

One issue that should be further examined is the responsiveness of the TFI, that is, the degree to which the TFI is able to assess changes in frailty status. Responsiveness of an instrument is positively related to the number of measures or components of the instrument. As the TFI contains a small number of items with sparse answering categories, which is considered a strength for most purposes, one may consider expanding the number of items of the TFI to increase its responsiveness. When considering expanding the TFI, we recommend adding items to the psychologic and social domains, for instance, items referring to feelings of insecurity and the number of social contacts. Apostolo et al ${ }^{67}$ recommend examining the responsiveness of frailty instruments, particularly in the context of community-based prevention programs. They argue that research should take into account the specificity of primary, secondary, and tertiary prevention, identifying frailty measures that are most appropriate in each of these contexts. ${ }^{67}$ More studies are also needed to establish whether the TFI is suitable for intervention studies not only in the community, but also in the hospital and for specific groups, such as patients admitted to an emergency department.

Another issue that needs attention refers to the weighting of components of the TFI. Previous studies have shown that applying weighted components can improve the predictive power of a frailty measure. ${ }^{93,94}$ However, the predictive power of the individual frailty components will depend strongly on the adverse outcome that will be examined. For example, Rothman et $\mathrm{al}^{95}$ showed that slow gait speed and cognitive impairment were the strongest predictors for disability and institutionalization, compared to five other frailty components including depressive symptoms, while Gobbens et $\mathrm{al}^{31}$ reported that depressive symptoms were the most important predictor of lower quality of life in older people. Therefore, for general purposes, we continue to rely on equal weighting.

So far, only a few studies have determined the predictive power of the TFI for the adverse outcome death, demonstrating that mortality risk increased with scores on the TFI. ${ }^{96,97}$ However, it should be noted that neither of these studies used the original TFI. Therefore, we recommend more studies focusing on the predictive value of the TFI for death in various settings; in particular, we are looking forward to the predictive validity of the individual frailty domains (physical, psychologic, social) and the 15 individual frailty components.

With respect to preventing or delaying frailty, other important research topics are the associations between lifestyle and frailty, ethnicity and frailty, and having a specific chronic disease or combinations of chronic diseases and frailty. Lifestyle is related to active aging and is also a relevant topic because it contains aspects where health care professionals should intervene. Previous research using the TFI showed that older people with an unhealthier lifestyle were more frail, even after controlling for sex, age, education, income, and multimorbidity; ${ }^{98}$ however, lifestyle was assessed with one question - "Overall, how healthy would you say your lifestyle is?" - with three answering categories: "healthy", "not healthy/not unhealthy", "unhealthy". For targeted interventions, more specific information about the lifestyle factors (eg, exercise, smoking, use of alcohol, nutrition) and their association with the score on the TFI total and its domains is necessary.

A previous study revealed some very large average frailty differences between ethnic groups (Dutch, Turks, Moroccans, Surinamese). ${ }^{32}$ Turks had the highest TFI score, followed by Moroccans and Surinamese. Moreover, it is known that ethnic minorities had an increased risk of unplanned hospital readmission within 30 days, ${ }^{99}$ and the total disease burden of ethnic minorities is likely to increase more than that of native Dutch. ${ }^{100}$ Therefore, we recommend additional research focusing on the associations of ethnicity and frailty and, in particular, on the sociodemographic characteristics and adverse outcomes in ethnic minorities. Interventions by health care professionals should be 
aimed at addressing the specific needs of frail older people belonging to ethnic minorities.

Previous TFI studies also showed that multimorbidity was associated with frailty. ${ }^{28,101}$ Due to the fact that multimorbidity was assessed mostly by one question - "Do you have two or more diseases and/or chronic diseases?" (yes/no) - we recommend further research focusing on the associations of individual chronic diseases and combinations of these diseases with frailty assessed with the TFI.

For the screening, assessment, and management of frailty, the recently developed guidelines by Dent et al are useful. ${ }^{102}$ One of the recommendations is the use of a validated measurement instrument to identify frailty. This review has demonstrated that we have several good instruments available, including the TFI. ${ }^{18}$ Unfortunately, in the guidelines, no recommendation was given for the provision of an individualized support and education plan for older people with frailty, although they emphasize that specific needs of older people themselves should be included in a support and education plan in order to promote independence and person-centered care. ${ }^{90,103}$ Therefore, first of all, it is important to determine not only the physical, psychologic, and social limitations that frail older people may have, but also to assess their strengths and opportunities (eg, informal care), so as to provide better insight into the frailty balance. Second, in order to be able to meet the individual needs of the frail person, collaboration between health care professionals, social workers, and the social network of the frail person is necessary. The essential goal of this collaboration is to arrive at a care and service arrangement that puts the frail older adult (or, if this is not possible, his or her social network) in control as much as possible.

\section{Conclusion}

In this review, we explored the efficiency of the TFI in assessing multidimensional frailty as a means to conduct research into the determinants and adverse outcomes of frailty and the use of the TFI in daily practice, as well as for future intervention studies. The TFI is based on an integral conceptual model of frailty; the instrument is easy and quick to administer and currently, there is robust evidence of its reliability and validity. Therefore, we recommend using the TFI in both research and practice. However, in our opinion, more studies are needed to establish whether the TFI is suitable for intervention studies not only in the community, but also for specific target groups, such as patients in the hospital or admitted to an emergency department. Furthermore, we conclude that it is important to not only determine the deficits that frail older people may have, but also to assess their balancing strengths and resources. In order to be able to meet the individual needs of frail older persons, traditional and often fragmented elderly care and welfare services should be developed toward a more proactive elderly care, in which frail older persons and their informal network are in charge.

\section{Disclosure}

The authors report no conflicts of interest in this work.

\section{References}

1. United Nations Department of Economic and Social Affairs. Population Division. World Population Prospects. The 2015 Revision. Key findings and Advance Tables. Working Paper No. ESA/P/WP.241. New York; 2015. Available from: http://esa.un.org/unpd/wpp/publications/files/ key_findings_wpp_2015.pdf. Accessed August 8, 2015.

2. van Bilsen PM, Hamers JP, Groot W, Spreeuwenberg C. Sheltered housing compared to independent housing in the community. Scand J Caring Sci. 2008;22(2):265-274.

3. WHO Centre for Health Development. A glossary of terms for community health care and services for older persons. Kobe, Japan: World Health Organization; 2004.

4. Gilleard C, Hyde M, Higgs P. The impact of age, place, aging in place on the well-being of the over 50s in England. Res Aging. 2007;29(6): 590-605.

5. Cutchin MP. The process of mediated aging-in-place: a theoretically and empirically based model. Soc Sci Med. 2003;57(6):1077-1090.

6. Mitzner TL, Chen TL, Kemp CC, Rogers WA. Identifying the potential for robotics to assist older adults in different living environments. Int J Soc Robot. 2014;6(2):213-227.

7. Horner B, Boldy DP. The benefit and burden of "ageing-in-place" in an aged care community. Aust Health Rev. 2008;32(2):356-365.

8. Marek KD, Stetzer F, Adams SJ, Popejoy LL, Rantz M. Aging in place versus nursing home care: comparison of costs to Medicare and Medicaid. Res Gerontol Nurs. 2012;5(2):123-129.

9. Rockwood K, Song X, MacKnight C, et al. A global clinical measure of fitness and frailty in elderly people. CMAJ. 2005;173(5):489-495.

10. Fried LP, Tangen CM, Walston J, et al; Cardiovascular Health Study Collaborative Research Group. Frailty in older adults: evidence for a phenotype. J Gerontol A Biol Sci Med Sci. 2001;56(3):M146-M156.

11. Kojima G, Iliffe S, Jivraj S, Walters K. Association between frailty and quality of life among community-dwelling older people: a systematic review and meta-analysis. J Epidemiol Community Health. 2016;70(7): 716-721.

12. Boyd CM, Xue QL, Simpson CF, Guralnik JM, Fried LP. Frailty, hospitalization, and progression of disability in a cohort of disabled older women. Am J Med. 2005;118(11):1225-1231.

13. Shamliyan T, Talley KM, Ramakrishnan R, Kane RL. Association of frailty with survival: a systematic literature review. Ageing Res Rev. 2013;12(2):719-736.

14. Vermeiren S, Vella-Azzopardi R, Beckwee D, et al. Frailty and the Prediction of Negative Health Outcomes: A Meta-Analysis. J Am Med Dir Assoc. 2016;17(12):1163.e1-1163.e17.

15. Rodriguez-Manas L, Feart C, Mann G, et al. Searching for an operational definition of frailty: a Delphi method based consensus statement: the frailty operative definition-consensus conference project. J Gerontol A Biol Sci Med Sci. 2013;68(1):62-67.

16. Gobbens RJ, Luijkx KG, Wijnen-Sponselee MT, Schols JM. Toward a conceptual definition of frail community dwelling older people. Nurs Outlook. 2010;58(2):76-86.

17. World Health Organization. World Report on Ageing and Health. Geneva, Switzerland; 2015.

18. Gobbens RJ, van Assen MA, Luijkx KG, Wijnen-Sponselee MT, Schols JM. The Tilburg Frailty Indicator: psychometric properties. J Am Med Dir Assoc. 2010;11(5):344-355. 
19. Sutton JL, Gould RL, Daley S, et al. Psychometric properties of multicomponent tools designed to assess frailty in older adults: a systematic review. BMC Geriatr. 2016;16(1):55.

20. Gobbens RJ, Luijkx KG, Wijnen-Sponselee MT, Schols JM. Towards an integral conceptual model of frailty. J Nutr Health Aging. 2010; 14(3):175-181.

21. Bergman H, Béland F, Karunananthan S, Hummel S, Hogan D, Wolfson C. English translation of article published in 'Gérontologie et société'. Dévelopment d'un cadre de travail pour comprendre et étudier la fragilité. Gérontol Société. 2004;109:15-29.

22. Fried LP, Ferrucci L, Darer J, Williamson JD, Anderson G. Untangling the concepts of disability, frailty, and comorbidity: implications for improved targeting and care. J Gerontol A Biol Sci Med Sci. 2004;59(3): 255-263.

23. Gobbens RJ, van Assen MA, Schalk MJ. The prediction of disability by self-reported physical frailty components of the Tilburg Frailty Indicator (TFI). Arch Gerontol Geriatr. 2014;59(2):280-287.

24. Abellan van Kan A, Rolland Y, Bergman H, Morley JE, Kritchevsky SB, Vellas B. The I.A.N.A Task Force on frailty assessment of older people in clinical practice. J Nutr Health Aging. 2008;12(1):29-37.

25. Xie B, Larson JL, Gonzalez R, Pressler SJ, Lustig C, ArslanianEngoren C. Components and Indicators of Frailty Measures: a literature review. J Frailty Aging. 2017;6(2):76-82.

26. Gobbens RJ, Luijkx KG, Wijnen-Sponselee MT, Schols JM. In search of an integral conceptual definition of frailty: opinions of experts. $\mathrm{J} \mathrm{Am}$ Med Dir Assoc. 2010;11(5):338-343.

27. Gobbens RJ, van Assen MA, Luijkx KG, Schols JM. The predictive validity of the Tilburg Frailty Indicator: disability, health care utilization, and quality of life in a population at risk. Gerontologist. 2012;52(5): 619-631.

28. Gobbens RJ, van Assen MA, Luijkx KG, Wijnen-Sponselee MT, Schols JM. Determinants of frailty. J Am Med Dir Assoc. 2010;11(5): 356-364.

29. Gill TM, Williams CS, Richardson ED, Tinetti ME. Impairments in physical performance and cognitive status as predisposing factors for functional dependence among nondisabled older persons. J Gerontol A Biol Sci Med Sci. 1996;51(6):M283-M288.

30. Strawbridge WJ, Shema SJ, Balfour JL, Higby HR, Kaplan GA. Antecedents of frailty over three decades in an older cohort. J Gerontol B Psychol Sci Soc Sci. 1998;53(1):S9-S16.

31. Gobbens RJ, Luijkx KG, van Assen MA. Explaining quality of life of older people in the Netherlands using a multidimensional assessment of frailty. Qual Life Res. 2013;22(8):2051-2061.

32. van Assen MA, Pallast E, Fakiri FE, Gobbens RJ. Measuring frailty in Dutch community-dwelling older people: reference values of the Tilburg Frailty Indicator (TFI). Arch Gerontol Geriatr. 2016;67:120-129.

33. Santiago LM, Luz LL, Mattos IE, Gobbens RJ, van Assen MA. Psychometric properties of the Brazilian version of the Tilburg frailty indicator (TFI). Arch Gerontol Geriatr. 2013;57(1):39-45.

34. Coelho T, Paul C, Gobbens RJ, Fernandes L. Frailty as a predictor of short-term adverse outcomes. PeerJ. 2015;3:e1121.

35. Uchmanowicz I, Gobbens RJ. The relationship between frailty, anxiety and depression, and health-related quality of life in elderly patients with heart failure. Clin Interv Aging. 2015;10:1595-1600.

36. Mulasso A, Roppolo M, Gobbens RJ, Rabaglietti E. Mobility, balance and frailty in community-dwelling older adults: What is the best 1-year predictor of falls? Geriatr Gerontol Int. Epub 2016 Sep 29.

37. Roppolo M, Mulasso A, Gobbens RJ, Mosso CO, Rabaglietti E. A comparison between uni- and multidimensional frailty measures: prevalence, functional status, and relationships with disability. Clin Interv Aging. 2015;10:1669-1678.

38. Gobbens RJ, van Assen MA, Luijkx KG, Schols JM. Testing an integral conceptual model of frailty. J Adv Nurs. 2012;68(9):2047-2060.

39. Gobbens RJ, van Assen MA. Frailty and its prediction of disability and health care utilization: the added value of interviews and physical measures following a self-report questionnaire. Arch Gerontol Geriatr. 2012;55(2):369-379.
40. Gobbens RJ, van Assen MA. The prediction of quality of life by physical, psychological and social components of frailty in communitydwelling older people. Qual Life Res. 2014;23(8):2289-2300.

41. Gonzalez-Colaco Harmand M, Meillon C, Bergua V, et al. Comparing the predictive value of three definitions of frailty: results from the threecity study. Arch Gerontol Geriatr. 2017;72:153-163.

42. Andreasen J, Sorensen EE, Gobbens RJ, Lund H, Aadahl M. Danish version of the Tilburg Frailty Indicator - Translation, cross-cultural adaption and validity pretest by cognitive interviewing. Arch Gerontol Geriatr. 2014;59(1):32-38.

43. Coelho T, Santos R, Paul C, Gobbens RJ, Fernandes L. Portuguese version of the Tilburg Frailty Indicator: transcultural adaptation and psychometric validation. Geriatr Gerontol Int. 2015;15(8):951-960.

44. Mulasso A, Roppolo M, Gobbens RJ, Rabaglietti E. The Italian Version of the Tilburg Frailty Indicator: analysis of psychometric properties. Res Aging. 2016;38(8):842-863.

45. Freitag S, Schmidt S, Gobbens RJ. Tilburg frailty indicator: German translation and psychometric testing. Z Gerontol Geriatr. 2016;49(2): 86-93.

46. Andreasen J, Lund H, Aadahl M, Gobbens RJ, Sorensen EE. Content validation of the Tilburg Frailty Indicator from the perspective of frail elderly. A qualitative explorative study. Arch Gerontol Geriatr. 2015; 61(3):392-399.

47. Uchmanowicz I, Jankowska-Polanska B, Loboz-Rudnicka M, Manulik S, Loboz-Grudzien K, Gobbens RJ. Cross-cultural adaptation and reliability testing of the Tilburg Frailty Indicator for optimizing care of Polish patients with frailty syndrome. Clin Interv Aging. 2014;9: 997-1001.

48. Uchmanowicz I, Jankowska-Polanska B, Uchmanowicz B, Kowalczuk K, Gobbens RJ. Validity and Reliability of the Polish Version of the Tilburg Frailty Indicator (TFI). J Frailty Aging. 2016;5(1): 27-32.

49. Ensrud KE, Ewing SK, Taylor BC, et al. Frailty and risk of falls, fracture, and mortality in older women: the study of osteoporotic fractures. J Gerontol A Biol Sci Med Sci. 2007;62(7):744-751.

50. Morley JE, Malmstrom TK, Miller DK. A simple frailty questionnaire (FRAIL) predicts outcomes in middle aged African Americans. J Nutr Health Aging. 2012;16(7):601-608.

51. Gill TM, Baker DI, Gottschalk M, Peduzzi PN, Allore H, Byers A. A program to prevent functional decline in physically frail, elderly persons who live at home. N Engl J Med. 2002;347(14):1068-1074.

52. Mitnitski AB, Mogilner AJ, Rockwood K. Accumulation of deficits as a proxy measure of aging. Scientific World Journal. 2001;1:323-336.

53. de Vries NM, Staal JB, Olde Rikkert MG, Nijhuis-van der Sanden MW. Evaluative frailty index for physical activity (EFIP): a reliable and valid instrument to measure changes in level of frailty. Phys Ther. 2013; 93(4):551-561.

54. Theou O, Brothers TD, Rockwood MR, Haardt D, Mitnitski A, Rockwood K. Exploring the relationship between national economic indicators and relative fitness and frailty in middle-aged and older Europeans. Age Ageing. 2013;42(5):614-619.

55. Hebert R, Bravo G, Korner-Bitensky N, Voyer L. Predictive validity of a postal questionnaire for screening community-dwelling elderly individuals at risk of functional decline. Age Ageing. 1996;25(2): 159-167.

56. Schuurmans H, Steverink N, Lindenberg S, Frieswijk N, Slaets JP. Old or frail: what tells us more? J Gerontol A Biol Sci Med Sci. 2004; 59(9):M962-M965.

57. Rolfson DB, Majumdar SR, Tsuyuki RT, Tahir A, Rockwood K. Validity and reliability of the Edmonton Frail Scale. Age Ageing. 2006; 35(5):526-529.

58. Brody KK, Johnson RE, Douglas Ried L. Evaluation of a self-report screening instrument to predict frailty outcomes in aging populations. Gerontologist. 1997;37(2):182-191.

59. Gloth FM 3rd, Walston J, Meyer J, Pearson J. Reliability and validity of the Frail Elderly Functional Assessment questionnaire. Am J Phys Med Rehabil. 1995;74(1):45-53. 
60. Saliba D, Elliott M, Rubenstein LZ, et al. The Vulnerable Elders Survey: a tool for identifying vulnerable older people in the community. $\mathrm{J} \mathrm{Am}$ Geriatr Soc. 2001;49(12):1691-1699.

61. Aguayo GA, Donneau AF, Vaillant MT, et al. Agreement Between 35 Published Frailty Scores in the General Population. Am J Epidemiol. 2017:1-15

62. Bouillon K, Kivimaki M, Hamer M, et al. Measures of frailty in population-based studies: an overview. BMC Geriatr. 2013;13:64.

63. Clegg A, Rogers L, Young J. Diagnostic test accuracy of simple instruments for identifying frailty in community-dwelling older people: a systematic review. Age Ageing. 2015;44(1):148-152.

64. de Vries NM, Staal JB, van Ravensberg CD, Hobbelen JS, Olde Rikkert MG, Nijhuis-van der Sanden MW. Outcome instruments to measure frailty: a systematic review. Ageing Res Rev. 2011;10(1): 104-114.

65. Pijpers E, Ferreira I, Stehouwer CD, Nieuwenhuijzen Kruseman AC. The frailty dilemma. Review of the predictive accuracy of major frailty scores. Eur J Intern Med. 2012;23(2):118-123.

66. Karunananthan S, Wolfson C, Bergman H, Beland F, Hogan DB. A multidisciplinary systematic literature review on frailty: overview of the methodology used by the Canadian Initiative on Frailty and Aging. BMC Med Res Methodol. 2009;9:68.

67. Apostolo J, Cooke R, Bobrowicz-Campos E, et al. Predicting risk and outcomes for frail older adults: an umbrella review of frailty screening tools. JBI Database System Rev Implement Rep. 2017;15(4): 1154-1208.

68. Castell MV, Sanchez M, Julian R, Queipo R, Martin S, Otero A. Frailty prevalence and slow walking speed in persons age 65 and older: implications for primary care. BMC Fam Pract. 2013;14:86.

69. Raiche M, Hebert R, Dubois MF. PRISMA-7: a case-finding tool to identify older adults with moderate to severe disabilities. Arch Gerontol Geriatr. 2008;47(1):9-18.

70. Podsiadlo D, Richardson S. The timed "Up \& Go": a test of basic functional mobility for frail elderly persons. J Am Geriatr Soc. 1991;39(2): $142-148$.

71. Jones DM, Song X, Rockwood K. Operationalizing a frailty index from a standardized comprehensive geriatric assessment. J Am Geriatr Soc. 2004;52(11):1929-1933.

72. Pialoux T, Goyard J, Lesourd B. Screening tools for frailty in primary health care: a systematic review. Geriatr Gerontol Int. 2012;12(2): 189-197.

73. Romero-Ortuno R, Walsh CD, Lawlor BA, Kenny RA. A frailty instrument for primary care: findings from the Survey of Health, Ageing and Retirement in Europe (SHARE). BMC Geriatr. 2010;10:57.

74. Cesari M, Gambassi G, van Kan GA, Vellas B. The frailty phenotype and the frailty index: different instruments for different purposes. Age Ageing. 2014;43(1):10-12.

75. Sav A, McMillan SS, Kelly F, et al. The ideal healthcare: priorities of people with chronic conditions and their carers. BMC Health Serv Res. 2015;15:551.

76. Kodner DL, Spreeuwenberg C. Integrated care: meaning, logic, applications, and implications - a discussion paper. Int J Integr Care. 2002;2:e12.

77. Jonker AA, Comijs HC, Knipscheer KC, Deeg DJ. The role of coping resources on change in well-being during persistent health decline. J Aging Health. 2009;21(8):1063-1082.

78. Hughes B, McKie L, Hopkins D, Watson N. Love's labours lost? Feminism, the disabled people's movement and an ethic of care. Sociology. 2005;39(2):259-275.

79. Watson N, McKie L, Hughes B, Hopkins D, Gregory S. (Inter)dependence, needs and care: The potential for disability and feminist theorists to develop an emancipatory model. Sociology. 2004;38(2):331-350.

80. Wiles JL, Wild K, Kerse N, Allen RE. Resilience from the point of view of older people: 'There's still life beyond a funny knee'. Soc Sci Med. 2012;74(3):416-424.

81. Rowe JW, Kahn RL. Successful aging and disease prevention. Adv Ren Replace Ther. 2000;7(1):70-77.
82. Nies H. Communities as co-producers in integrated care. Int J Integr Care. 2014;14:e022.

83. Baltes MM, Lang FR. Everyday functioning and successful aging: the impact of resources. Psychol Aging. 1997;12(3):433-443.

84. Lazarus RS, Lazarus BN. Coping with aging. Oxford, UK: Oxford University Press; 2006.

85. Sipsma DH. Sociale geriatrie in theorie en praktijk [Academic Thesis University of Groningen/University Medical Center Groningen]. Almere, the Netherlands: Promeda; 1986. Dutch.

86. De Blok C, Meijboom B, Luijkx KG, Schols J. The human dimension of modular care provision: Opportunities for personalization and customization. Int J Prod Econ. 2013;142(1):16-26.

87. Lloyd-Sherlock P. Identifying vulnerable older people. Ageing Soc. 2006;26(1):81-103.

88. Ament BHL, de Vugt ME, Verhey FRJ, Kempen GIJM. Are physically frail older persons more at risk of adverse outcomes if they also suffer from cognitive, social, and psychological frailty? Eur J Ageing. 2014; 11(3):213-219.

89. Dedeyne L, Deschodt M, Verschueren S, Tournoy J, Gielen E. Effects of multi-domain interventions in (pre)frail elderly on frailty, functional, and cognitive status: a systematic review. Clin Interv Aging. 2017; 12:873-896.

90. Bengtson VL, Settersten Jr RA. Handbook of theories of aging. Third ed. New York: Springer Publishing Company; 2016.

91. Hooyman NR, Mahoney KJ, Sciegaj M. Theories that guide consumerdirected/person-centered initiatives in policy and practice. In: Bengtson VL, Settersten Jr RA, eds. Handbook of theories of aging Third ed. New York: Springer Publishing Company; 2016:427-442.

92. Dunér A, Nordström M. Intentions and strategies among elderly people: Coping in everyday life. J Aging Stud. 2005;19(4):437-451.

93. Kamaruzzaman S, Ploubidis GB, Fletcher A, Ebrahim S. A reliable measure of frailty for a community dwelling older population. Health Qual Life Outcomes. 2010;8:123.

94. Theou O, Brothers TD, Mitnitski A, Rockwood K. Operationalization of frailty using eight commonly used scales and comparison of their ability to predict all-cause mortality. J Am Geriatr Soc. 2013;61(9): 1537-1551.

95. Rothman MD, Leo-Summers L, Gill TM. Prognostic significance of potential frailty criteria. J Am Geriatr Soc. 2008;56(12):2211-2216.

96. Theou O, Brothers TD, Pena FG, Mitnitski A, Rockwood K. Identifying common characteristics of frailty across seven scales. J Am Geriatr Soc. 2014;62(5):901-906.

97. Huisman M, Deeg D. The course of frailty. In: van Campen C, ed. Frail older persons in the Netherlands. The Hague: The Netherlands Institute for Social Research; 2011:83-90.

98. Gobbens RJ, van Assen MA. Explaining frailty by lifestyle. Arch Gerontol Geriatr. 2016;66:49-53.

99. de Bruijne MC, van Rosse F, Uiters E, et al. Ethnic variations in unplanned readmissions and excess length of hospital stay: a nationwide record-linked cohort study. Eur J Public Health. 2013;23(6): 964-971.

100. Ikram UZ, Kunst AE, Lamkaddem M, Stronks K. The disease burden across different ethnic groups in Amsterdam, the Netherlands, 2011-2030. Eur J Public Health. 2014;24(4):600-605.

101. Coelho T, Paul C, Gobbens RJ, Fernandes L. Determinants of frailty: the added value of assessing medication. Front Aging Neurosci. 2015;7:56.

102. Dent E, Lien C, Lim WS, et al. The Asia-Pacific Clinical Practice Guidelines for the Management of Frailty. J Am Med Dir Assoc. 2017;18(7):564-575

103. Senior HE, Parsons M, Kerse N, et al. Promoting independence in frail older people: a randomised controlled trial of a restorative care service in New Zealand. Age Ageing. 2014;43(3):418-424. 


\section{Supplementary material}

\section{Part A Determinants of frailty}

1. Which sex are you?
$\square$ Male
Female

2. What is your age? years

3. What is your marital status?
$\square$ Married/living with partner
$\square$ Unmarried
Separated/divorced
Widow/widower

4. In which country were you born?
$\square$ the Netherlands
Former Dutch East Indies
Suriname
$\square$ the Netherlands Antilles
$\square$ Turkey
Morocco
Other, namely.

5. What is the highest level of education you have completed?
$\square$ None or primary education
$\square$ Secondary education
$\square$ Higher professional or university education

6. Which category indicates your net monthly household income?
$\square € 600$ or less
$\square € 601-€ 900$
$\square € 901-€ 1200$
$€ 1201-€ 1500$
$\square € 1501-€ 1800$
$\square € 1801-€ 2100$
$\square € 2101$ or more

7. Overall, how healthy would you say your lifestyle is?
$\checkmark$ Healthy
$\square$ Not healthy, not unhealthy
Unhealthy

8. Do you have two or more diseases and/or chronic disorders?
$\square$ Yes
$\square$ No

9. Have you experienced one or more of the following events during the past year?

- the death of a loved one
$\square$ Yes
No
- a serious illness yourself
$\square$ Yes
$\square$ No
- a serious illness in a loved one
$\square$ Yes
$\square$ No
- a divorce or ending of an important intimate relationship
$\square$ Yes
$\square$ No
- a traffic accident
$\square$ Yes
No
- a crime
$\square$ Yes $\quad \square$ No

10. Are you satisfied with your home living environment?
$\square$ Yes
$\square$ No

\section{Part B Components of frailty}

\section{B1 Physical components}

11. Do you feel physically healthy?
$\square$ Yes
$\square$ No

12. Have you lost a lot of weight recently without wishing to do so?

("a lot" is $6 \mathrm{~kg}$ or more during the last 6 months or $3 \mathrm{~kg}$ or more during the last month)
$\square$ Yes
$\square$ No

Figure SI (Continued) 
Do you experience problems in your daily life due to:

13. difficulty in walking?
$\square$ Yes
$\square$ No

14. ..........difficulty maintaining your balance?
$\square$ Yes
$\square$ No

15. poor hearing?
$\square$ Yes
$\square$ No

16. poor vision?

$\square$ Yes $\square$ No

17. ..........lack of strength in your hands?
$\square$ Yes
$\square$ No

18. ..physical tiredness?
$\square$ Yes
$\square$ No

\section{B2 Psychological components}

19. Do you have problems with your memory?
$\square$ Yes
$\square$ Sometimes
No

20. Have you felt down during the last month?
$\square$ Yes
$\square$ Sometimes
No

21. Have you felt nervous or anxious during the last month?
$\square$ Yes
$\square$ Sometimes
$\square$ No

22. Are you able to cope with problems well?
$\square$ Yes
$\square$ No

\section{B3 Social components}

23. Do you live alone?
$\square$ Yes
$\square$ No

24. Do you sometimes miss having people around you?
$\square$ Yes
$\square$ Sometimes
No

25. Do you receive enough support from other people?
$\square$ Yes
$\square$ No

\section{Scoring Part B Components of frailty (range: 0-15)}

Question 11:

Questions 12-18:

Question 19:

Questions 20 and 21:

Question 22:

Question 23:

Question 24:

Question 25: $\square$ Yes $=0$,

$\square \mathrm{No}=0$,

$\square$ No and Sometimes $=0$,

$\square \mathrm{No}=0$,

$\square$ Yes $=0$,

$\square \mathrm{No}=0$,

$\square \mathrm{No}=0$,

$\square$ Yes $=0$, $\square \mathrm{No}=1$

$\square$ Yes $=1$

$\square$ Yes $=1$

$\square$ Yes and Sometimes $=1$

$\square \mathrm{No}=1$

$\square$ Yes $=1$

$\square$ Yes and Sometimes $=1$

$\square \mathrm{No}=1$

Figure SI The Tilburg Frailty Indicator (TFI)

Note: Reprinted from J Am Med Dir Assoc. I I(5). Gobbens RJ, van Assen MA, Luijkx KG, Wijnen-Sponselee MT, Schols JM. The Tilburg Frailty Indicator: psychometric properties. 344-355. Copyright (2010), with permission from Elsevier.'

\section{Reference}

1. Gobbens RJ, van Assen MA, Luijkx KG, Wijnen-Sponselee MT, Schols JM. The Tilburg Frailty Indicator: psychometric properties. J Am Med Dir Assoc. 2010;11(5):344-355. 


\section{Publish your work in this journal}

Clinical Interventions in Aging is an international, peer-reviewed journal focusing on evidence-based reports on the value or lack thereof of treatments intended to prevent or delay the onset of maladaptive correlates of aging in human beings. This journal is indexed on PubMed Central, MedLine,

CAS, Scopus and the Elsevier Bibliographic databases. The manuscript management system is completely online and includes a very quick and fair peer-review system, which is all easy to use. Visit http://www.dovepress. com/testimonials.php to read real quotes from published authors. 